\title{
Localisation of logistics preparedness in international humanitarian organisations
}

Localisation of logistics preparedness

Lina Frennesson and Joakim Kembro

Department of Industrial Management and Logistics, Lund University, Lund, Sweden Harwin de Vries

Rotterdam School of Management, Erasmus University, Rotterdam, The Netherlands Luk Van Wassenhove

TOM, INSEAD, Fontainebleau, France, and

Marianne Jahre

Department of Industrial Management and Logistics, Lund University, Lund, Sweden and

Department of Accounting, Auditing and Business Analytics, BI Norwegian Business School, Oslo, Norway

\begin{abstract}
Purpose - To meet the rising global needs, the humanitarian community has signed off on making a strategic change toward more localisation, which commonly refers to the empowerment of national and local actors in humanitarian assistance. However, to this date, actual initiatives for localisation are rare. To enhance understanding of the phenomenon, the authors explore localisation of logistics preparedness capacities and obstacles to its implementation. The authors particularly take the perspective of the international humanitarian organisation (IHO) community as they are expected to implement the localisation strategy.

Design/methodology/approach - A phenomenon-driven, exploratory and qualitative study was conducted. Data collection included in-depth interviews with 28 experienced humanitarian professionals.

Findings - The findings showed the ambiguity inherent in the localisation strategy with largely different views on four important dimensions. Particularly, the interviewees differ about strengthening external actors or internal national/local offices. The resulting framework visualises the gap between strategy formulation and implementation, which forms major obstacles to the localisation aims.

Research limitations/implications - Further research is required to support the advancement of localisation of logistics preparedness capacities. Important aspects for future research include triangulation of results, other stakeholder perspectives and the influence of context.

Practical implications - The authors add to the important debate surrounding localisation by offering remedies to overcoming obstacles to strategy implementation. Further, the authors' proposed framework offers a language to precisely describe the ways in which IHOs (should) view localisation of logistics preparedness capacities and its operationalisation.
\end{abstract}

Originality/value - To the best of authors' knowledge, this paper is the first academic article on localisation within the humanitarian logistics context.

Keywords Localisation, Preparedness, Disaster relief, Capacity strengthening, Humanitarian logistics,

Humanitarian supply chains

Paper type Research paper

(C) Lina Frennesson, Joakim Kembro, Harwin de Vries, Luk Van Wassenhove and Marianne Jahre. Published by Emerald Publishing Limited. This article is published under the Creative Commons Attribution (CC BY 4.0) licence. Anyone may reproduce, distribute, translate and create derivative works of this article (for both commercial and non-commercial purposes), subject to full attribution to the original publication and authors. The full terms of this licence may be seen at http://creativecommons. org/licences/by/4.0/legalcode

This research was funded by the Crafoord Foundation.
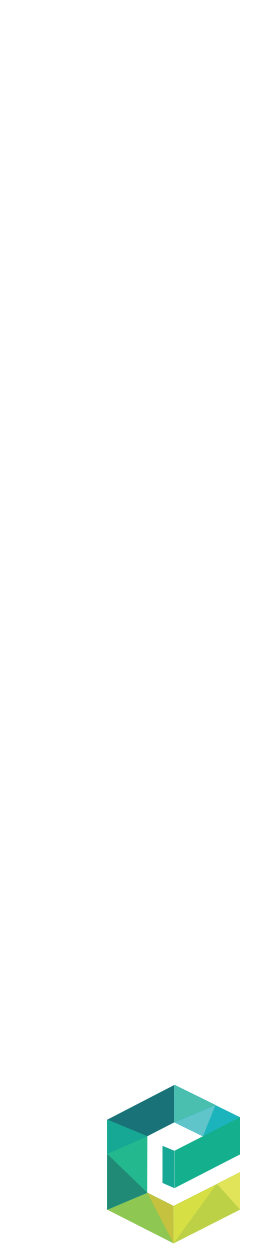


\section{JHLSCM 11,1}

\section{Introduction}

Localisation is a prevalent topic in the humanitarian community, often referring to the inclusion and empowerment of national and local actors in humanitarian assistance. Localisation represents a radical reform and a major strategic shift of the humanitarian system, promoting local responsibility and including a more diverse set of local actors to respond to disasters (Currion, 2018). Several practitioners (see, e.g., Stoddard et al., 2015; Bennett et al., 2016; Collinson, 2016) deem the shift as essential to meet rising global needs and to address some of the inadequacies and inefficiencies inherent in the current closed humanitarian system. These include the system being hierarchal, Western-biased and bureaucratic, with power residing at a few international organisations and donors. Stoddard et al. (2015) argue that the capacity of the humanitarian system is limited by the lacking ability to recognise, include, strengthen and build on existing national and local capacities. Advocates for localisation further emphasise the potential for a more sustainable, effective, rapid, accountable and context-adapted response (Ramalingam et al., 2013; ICVA, 2018).

The need for change has been recognised by large international humanitarian organisations (IHOs) and donors who have committed to several international strategic initiatives for increased localisation. The most prominent initiatives are the Grand Bargain and the Charter for Change. The Grand Bargain's second work stream commits 62 of the largest IHOs and donors to directly donate $25 \%$ of the global humanitarian funds to national and local responders by 2020 as well as to invest in their institutional capacities, including preparedness (Agenda for Humanity, 2016, p. 11). The Charter for Change, signed by 35 international non-governmental organisations (INGOs), consists of eight commitments that aim at giving national actors "an increased and more prominent role in humanitarian response" (Charter4Change, 2019). United Nations (UN) Sustainable Development Goals also point in the direction of localisation, including Goal 11 "sustainable cities and communities" and Goal 13 "climate action". Target 13.1, for example, aims to "strengthen resilience and adaptive capacity to climate-related hazards and natural disasters in all countries" (United Nations, 2019).

Despite the formulation of strategic initiatives and abundant practitioner literature on the topic, localisation as a concept appears to be surrounded by confusion and ambiguity. There is no sector-wide accepted definition of localisation, and it is often confused with decentralisation, which is commonly argued to be a strengthening of IHOs' affiliated regional, national, or subnational offices (Van Brabant and Patel, 2018). One report states that localisation is an umbrella term that is "used to refer to any and all activities considered to involve local actors" (Wall and Hedlund, 2016, p. 11). Other reports highlight that the Grand Bargain signatories lack a shared vision of localisation (ICVA, 2018) and that the ultimate goal of localisation is uncertain (Metcalfe-Hough et al., 2018). These varying views point to a lack of shared strategy formulation, which could be problematic as it hampers successful implementation (Hill et al., 2015). Hence, the question arises: how is the humanitarian community progressing with implementing the major strategic change that localisation represents? Setting out to answer this question, we specifically consider the IHO perspective as they are the ones implementing the localisation strategy agreed by the humanitarian community. This strategy requires, according to De Geoffroy and Grunewald (2017, p. 4), "a shift in power relations between actors, both in terms of strategic decision-making and control of resources". As first-level recipients, IHOs receive a majority of international humanitarian response funding with only $2.1 \%$ in 2019 directed to national and local responders (Thomas and Urquhart, 2020). IHOs thus possess power, capacities and knowledge that must be shared, and successful localisation heavily relies on their abilities to implement the localisation strategy. In the long term, changes in the fundamental structures that underpin the humanitarian system, such as funding policies, are required. It is however not within the scope of this paper. 
We address localisation specifically in terms of logistics preparedness, a key area in humanitarian assistance (Jahre et al., 2016) that involves preparing for the supply and distribution of necessary items and services to beneficiaries. Firstly, logistics - including the value of purchased items - constitutes up to $80 \%$ of response budgets (Van Wassenhove, 2006; Stumpf et al., 2017). Secondly, preparedness is essential to the success of humanitarian aid interventions. Researchers and practitioners alike agree that a dollar invested in preparedness saves multiple dollars in disaster response. A recent study estimated that every dollar invested in preparedness saves between 2.3 and 13.2 dollars in disaster response (Lewin et al.,2018), depending on the type and location of the disaster. Logistics preparedness capacities are therefore essential for IHOs, and localisation plays an important role in the pursuit of more effective and efficient operations, making it a natural area for our investigation.

In this paper, we seek to enhance the understanding of localising logistics preparedness capacities. Responding to the call for research with more practical relevance (Kunz et al., 2017), the following research questions are formulated:

(1) What are the obstacles to implementing the localisation strategy of logistics preparedness?

(2) How can localisation of logistics preparedness capacities be operationalised?

This paper is one of the first academic articles on localisation within the humanitarian logistics context. Our study shows that several obstacles hinder implementation of the localisation strategy and offers insights to reasons for this (and therefore also the remedies), as seen from the IHOs themselves. Particularly, we find that it is not clear what is meant by localisation and how it is operationalised. Even in the crucial action-oriented logistics area, the localisation strategy is unclear with confusion between strengthening external actors and internal national/local offices. In addition, we find that there is more tendency to localise capacities directly related to logistics operations than for example coordination skills and knowledge on how to attract funding.

We contribute to the important debate surrounding localisation by showing the gap between strategy formulation and its implementation. This finding is important and in line with recent thinking in strategy research, which highlights that strategies do not mean anything if they cannot be implemented (e.g. Lee and Puranam, 2016; Ates et al., 2020). We further add to the localisation debate by proposing a language to precisely describe the ways in which IHOs (should) view localisation of logistics preparedness and its operationalisation. This is done bottom-up as we analyse, condense and classify localisation views of 28 interviewees from 12 IHOs. Based on our analysis, we develop a framework, which helps the humanitarian community to understand and in the future address some of the obstacles to implementing the localisation strategy.

Next, we discuss related literature used to develop the interview guide and interpret the empirical findings. Then follows the methodology. Section four describes and summarises the empirical findings. Finally, we conclude and suggest avenues for further research.

\section{Related literature}

For the purpose of our paper, we consider four pillars of literature. First, we explore the meaning of localisation, both in scientific and grey literature. Second, we review the range and roles of humanitarian actors at the local level, focussing on how IHOs function within countries. Third, we take a closer look at what constitutes logistics preparedness. Finally, we include strategy implementation literature as a foundation for understanding and discussing our findings. 


\section{JHLSCM 11,1}

\section{4}

\subsection{Localisation}

Localisation research in humanitarian logistics literature is largely absent. The term localisation is however in a broad sense not novel with research exploring localisation in a commercial supply chain setting. Commercial localisation often refers to a company's internal process of entering new markets, performing main activities locally, and adapting products and services to the local context (Ben-Ner and Siemsen 2017; Wu and Jia, 2018). The intention of humanitarian localisation concerns shifting power and capacity to external local actors (see, e.g. Bennett et al., 2016). This significant difference suggests the occurrence of two separate phenomena sharing the same term. Therefore, we consider commercial localisation research as less useful for analysing the empirical findings of this paper.

The amount of practitioner literature on localisation is substantial. Various reports cover the localisation discourse, the reasons to localise, the main challenges, and practical guidance on its execution. Considering our study's focus on strategy formulation and its implementation, we review the main reports on localisation discourse. Localisation is argued to be the newest buzzword for the decades-old debate on how to achieve a more local response and strengthen local capacity (see, e.g. Wall and Hedlund, 2016; Fast and Bennett, 2020). Despite the longstanding, continuous discussion and various initiatives, many reports express frustration over the humanitarian sector's inability to walk the talk. Reports state that IHOs do not prioritise partnering with national and local actors and that they lack handover strategies (Ramalingam et al., 2013; De Geoffroy and Grunewald, 2017). Some criticism concerns the localisation term itself, with arguments that it "reflects an international-centric reform agenda" (Fast and Bennett, 2020, p. 7). A few reports advocate that the terms "locally-led" or "local humanitarian action" better reflect the aims of building on existing local capacities (Barbelet, 2018). Others highlight international actors' main role in shifting power and resources to national and local actors (Bennett et al., 2016; De Geoffroy and Grunewald, 2017).

The definition of a national or local actor is a recurring and highly relevant theme for the localisation debate. National and local are ambiguous terms, which affect how localisation is interpreted. This is evident in Van Brabant and Patel's (2018) two identified localisation interpretations in humanitarian discourse: "decentralisation" and "transformation". A "decentralisation interpretation" considers a national/local actor as a geographically induced term which therefore includes IHOs' country offices and affiliations. In this interpretation, the aim of localisation is to tackle the issue of IHOs becoming too centralised, with the solution to transfer capacity and decision-making geographically closer to the people at risk. Opponents to this interpretation argue that "decentralisation" is problematic as it leads to a multi-nationalisation of IHOs rather than diversity of actors in the humanitarian sector. Internationally affiliated organisations also risk outcompeting independent national and local actors in fundraising. Advocates for the "transformation interpretation" argue that localisation's aim is to increase the authority and capacity of national/local actors not affiliated to an IHO. This is argued to be a more sustainable approach to disaster management and addresses the political, financial and power unbalances between IHOs and independent national/local actors. Van Brabant and Patel (2018) further discuss that localisation should be interpreted as transformation rather than decentralisation, which is supported in the Grand Bargain and the Charter for Change. Barbelet (2018, p. 7) adds to the discussion by stating: "While national staff still working in international organisations would not be considered part of local capacity because their work is contributing to the objectives and agendas of an international organisation, it is important to recognise the career path and experience of national staff as contributing at some point to local capacity". To conclude, a majority of practitioner reports distinguish between strengthening national/local affiliates to IHOs and independent actors. 
2.2 Humanitarian actors at the local level

While localisation studies are largely absent in scientific humanitarian logistics literature, there are papers on local operations and the various actors involved at the local level. A majority of papers devote a significant amount of attention to humanitarian organisations and, especially, IHOs. Although IHOs have traditionally been considered the primary providers of aid, there is a range of other actors that play a crucial role. Local level actors include diverse national/local organisations, host governments (e.g. national disaster management authorities, fire-rescue, police and hospitals), private companies and beneficiaries. Although responsibilities and mandates differ from country to country, each actor is typically present in a disaster response. Collaboration efforts are frequently made but are context-specific and depend on the disaster type and phase (Prasanna and Havisto, 2018).

Humanitarian organisations range from IHOs to national/local non-governmental organisations (NGOs) and civil-society organisations (CSOs). CSOs include a variety of voluntary organisations and associations, such as various faith-based or community-based ones. Despite the many national and local organisations engaged in humanitarian assistance, IHOs are often in control of decisions and resources because of their size and global influence. They also frequently work in a decentralised setting with a permanent presence in the countries in which they operate, using locally procured goods and employing local staff (Van Wassenhove, 2006; Bhattacharya et al., 2014). Although some IHO operations can be considered local in nature, the decision-making often resides with expatriates instead of local staff (Pedraza-Martinez et al., 2011; Bealt and Mansouri, 2018). National/local NGOs and CSOs are not as well researched as IHOs in humanitarian logistics (Jahre, 2017) but they are often highlighted as important collaborating partners in local response work (e.g. Perry, 2007; Balcik et al., 2010). They already have "boots on the ground", strong connections with local populations, and operate vast networks in their respective countries. This makes them relatively well-equipped to act as first responders to disasters and perform last-mile distribution (Holguín-Veras et al., 2012a). Furthermore, they tend to have adequate cultural understanding and knowledge of the beneficiaries' needs (Bealt and Mansouri, 2018). Therefore, they often act as advocates for their communities. Even so, they are, according to Roepstorff (2020), systematically marginalised in the humanitarian sector, both in terms of media attention and funding, and IHOs often use them as subcontractors.

Other key stakeholders in logistics preparedness initiatives are the beneficiaries and their communities (Sheppard et al., 2013), which act as first responders (Roepstorff, 2020). Several studies stress the involvement of local populations as a key determinant of any relief effort's success (e.g. Pardasani, 2006; Perry, 2007, Méheux et al., 2010, Sheppard et al., 2013). Examples include members of the local community participating in aid distribution, using local knowledge when planning a response and performing a needs assessment. Bealt and Mansouri (2018) argue that some of the preparedness capacities and abilities provided by IHOs already exist within local communities; they just need to be tapped. Local businesses as well as international, commercial businesses are also important actors in the humanitarian sector. Some private companies are donors, while others participate in actual disaster response operations (Nurmala et al., 2018). For economic and sustainability reasons as well as to support local economies, IHOs increasingly use local suppliers and logistics service providers (Kovács and Spens, 2011; Zarei et al., 2019). For smaller disasters, local businesses often form the main source of relief (Holguín-Veras et al., 2012a). The private sector is also critical in helping a society recover and return to its normal state (Holguín-Veras et al., 2012b).

Other important actors are host governments who, per definition, are responsible for humanitarian assistance in their sovereign states. If the capacity of the host government is insufficient, international help is called upon. Even though host governments in those cases often channel their activities through IHOs they control central resources and processes, such as warehouses and customs clearance (Kovács and Spens, 2007; Kunz and Gold, 2017). Some
Localisation of logistics preparedness 
JHLSCM 11,1

IHOs, especially INGOs, have a complex relationship with host governments. INGOs are dependent on host governments for access to the country and freedom to operate, but at the same time require to work independently on their own terms. This can create tensions in interests (Dube et al., 2016). Donors represent another key stakeholder at the local level. They provide the main proportion of funding to IHOs and therefore influence possibilities of building logistics preparedness capacities, but are not involved in local operations per se.

In short, extant literature acknowledges the importance of national/local actors' involvement in logistics preparedness. We refer to external, national/local actors as an inclusive term for actors that (1) primarily operate within their own country's borders and (2) are not a part of or affiliated with an IHO (i.e. external to the IHO). These include host governments, national/local NGOs/CSOs, the private sector and communities/beneficiaries. A few papers have highlighted the need for increasing the autonomy of external, national/ local actors. For example, Sheppard et al. (2013) argue that having governments and local actors take the lead with preparedness would improve the speed, efficiency and sustainability of their response. However, a comprehensive understanding of the localisation process itself is currently lacking.

\subsection{Logistics preparedness capacities}

Preparedness is considered a cornerstone of disaster management (see, e.g. Coppola, 2007; Haddow et al., 2010). United Nations members have reconfirmed its importance through the Sendai Framework for Disaster Risk Reduction 2015-2030, which focuses on reducing disaster risk and disasters' destructive effects (UNISDR, 2019a). As one of four top priorities, the framework acknowledges the importance of enhancing preparedness for more effective response and recovery. The intensified economic and social impacts of disasters partly explain the current focus on preparedness in the humanitarian sector (CRED, 2018). Moreover, IHO funding constraints call for innovative use of available resources. Most researchers and practitioners agree that shifting resources from reactive response to preparedness initiatives are key opportunities for doing so (Lewin et al., 2018).

Preparedness has been defined in many ways. For example, the UN defines it as "[t]he knowledge and capacities developed by governments, response and recovery organisations, communities and individuals to effectively anticipate, respond to and recover from the impacts of likely, imminent or current disasters" (UNISDR, 2019b). Other definitions include "actions taken in advance of a disaster to ensure adequate response to its impacts, and the relief and recovery from its consequences" (Coppola, 2007, p. 209) or simply "readiness to respond to a disaster" (Haddow et al., 2010, p. 121). As seen from these definitions, preparedness is often explained in general terms and spans a vast range of activities, stakeholders and resources. The UN definition, henceforth used in this paper, connects preparedness to another closely related term: capacities. The UN defines capacity as "the combination of all the strengths, attributes and resources available within an organisation, community or society to manage and reduce disaster risks and strengthen resilience" (UNISDR, 2019b). Resilience, in this sense, refers to the ability of a society to both resist and handle the effects of a disaster in a timely and efficient manner (Bhamra et al., 2011).

We specifically focus on the localisation of logistics preparedness capacities. Jahre et al. (2016, p. 383) define logistics preparedness as "[t]he implementation of processes, structures, and systems connecting local community, national and international actors by designing, planning and training for efficient, effective and responsive mobilisation of material, financial, human and informational resources when and where needed. This encompasses a range of activities, including needs assessment, procurement, warehousing, transporting and distributing, waste management and performance measurement for the purpose of alleviating the suffering of vulnerable people". We thus refer to logistics preparedness 
capacities as the logistics strengths, attributes, and resources to effectively anticipate, respond to, and recover from the impacts of disasters.

\subsection{Strategy implementation}

The localisation aim within the humanitarian community represents a major strategic shift in how aid is provided. Its success depends largely on IHOs' ability to implement the formulated strategy. Strategy implementation (sometimes referred to as execution) is defined by Lee and Puranam (2016, p. 1529) as "the extent to which an organisation's actions correspond to its strategic intentions". It demands an organisation wide effort with strategic goals aligned to key organisational factors (Porck et al., 2020). Nielson et al. (2008, p. 83) view implementation more at an individual level, stating that it is "the result of thousands of decisions made every day by employees acting according to the information they have and their own self-interest". Lee and Puranam (2016) argue that organisations should always pursue precise implementation, independent of the formulated strategy's appropriateness. Precise implementation can function as a learning process, allowing organisations to analyse the intended strategy through feedback and bottom-up exploration.

Researchers agree that strategy implementation is much more difficult than strategy formulation as it requires substantial and sustainable changes throughout the whole organisation. For non-profit organisations, there is additional complexity in handling "the pressures of fiscal, political and social concerns in addition to dividing attention among stakeholder groups" (Lewis et al., 2001, p. 8). Implementation is in general seen as less glamorous than formulation and filled with uncertainties to what it includes, where it begins, and where it ends (Alexander, 1991).

The literature highlights numerous obstacles to successful strategy implementation. One common is resistance to change and lack of strategic commitment (Hrebiniak, 2006; Ateş et al., 2020). According to Sharp and Brock (2012), nonprofit organisations often resist strategic change, viewing it as a threat to their survival and the organisation's mission, core values, or mode of operation. Other common obstacles include lack of communication, instructions, and coordination of implementation activities (Alexander, 1985). This could result in an absence of strategic consensus where teams and employees prioritise and interpret the strategy differently (Porck et al., 2020).

To overcome obstacles, clarity is key - both at an organisational level with the formulation of an understandable strategy and at an individual level with distinct decision rights and responsibility (Neilson et al., 2008). The strategy must be connected to the organisational goals and the employees' day-to-day objectives, making extensive communication to all employees essential (Alexander, 1985; Zagotta and Robinson, 2002). Hrebiniak (2006) argues that the organisation should create an implementation guide to help employees understand and apply the strategy. While communication maximises the potential of strategic consensus, strategic commitment is desired to motivate employees to align their work to the strategy and collaborate better with others (Ateş et al., 2020). This can be facilitated by visionary leadership, shared goals, and reduced uncertainty around the change process.

Finally, research suggests that strategic aims must be quantified and integrated with performance measurements to assist employees in making strategy aligned decisions. This may also help create strategic commitment as "realistic quantification transforms potentially lofty statements into believable goals that create positive clarity, energy and commitment throughout the organisation" (Zagotta and Robinson, 2002, p. 31).

\section{Methodology}

3.1 Research strategy and data selection

Due to the newness of the localisation topic in humanitarian logistics research, we conducted a phenomenon-driven, exploratory, and qualitative study. Phenomenon-driven research

Localisation of logistics preparedness 
JHLSCM 11,1

\section{8}

Figure 1.

Data selection process

focuses on "identifying, capturing, documenting and conceptualising a phenomenon of interest in order to facilitate knowledge creation and advancement" (Schwarz and Stensaker, 2014, p. 486) and is significant for theory building (Von Krogh et al., 2012). Early phases of phenomenon-based research are best supported by qualitative research, as there is no theory that can be tested (Edmondson and McManus, 2007). Robson (2002, p. 59) argues that the exploratory approach is suitable for identifying "what is happening; to seek new insights; to ask questions and to assess phenomena in a new light".

As illustrated in Figure 1, the unit of analysis in our research is the community of IHOs. The initiatives on localisation concern the whole humanitarian sector (Fabre, 2017; Charter4Change, 2019; Fast and Bennett, 2020). We selected IHOs considering that they are the prime stakeholders in implementing commonly accepted localisation initiatives. Lately, IHOs' prominent and powerful position in the closed humanitarian community has been increasingly questioned and considered an obstacle to more effective and inclusive humanitarian aid (Bennett et al., 2016; Currion, 2018). The imminent success of implementing the localisation strategy hinges on IHOs' ability and willingness to share their capacity and in-depth knowledge with national and local actors. In a long-term perspective, localisation necessitates a change in the fundamental structures of the humanitarian system. It is therefore important that other studies account for donors' perspective alongside other stakeholders. In the imminent future however, IHOs must lead the humanitarian sector on this new path.

Although strategy implementation literature concerns individual organisations, it is relevant for our study as the humanitarian community is relatively small, organisations often work closely together and employees tend to move across organisations. In such close collaborations and with a sector-wide strategic aim, a common understanding of localisation is essential. As seen in strategy implementation literature, implementation consists of all the decisions made by employees (Nielson et al., 2008). IHO employees are thus the central nodes in the network that makes localisation possible. Therefore, they are best suited to provide input on the IHO perspective to the localisation agenda and for understanding obstacles to its implementation. We chose interviews as the primary source of data. Conducting interviews supports the exploratory approach (Von Krogh et al., 2012) and gives the opportunity to collect empirical material from a wide range of individuals working in the IHO community.

In order to cover as many IHO-localisation views as possible, we set out to obtain a sample of interviewees representing various IHOs from the three large clusters. These include UN-agencies, the International Federation of the Red Cross and Red Crescent Societies (IFRC), and INGOs. We used the following inclusion criteria to determine our sample (Miles and Huberman, 1994). First, the IHO had to deliver products and/or services as part of its humanitarian assistance, and logistics had to be an essential part of its operations. Second, the IHO had to have a strong emphasis on preparedness and disaster relief. Third, the IHO had to cover a large geographical area to allow for comparisons between different contexts. We specifically used "operating on all continents" as a criterion. Among the possible
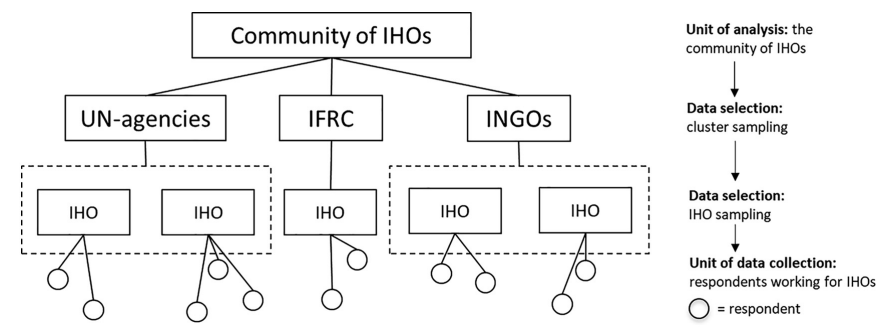
candidates, 12 IHOs were selected (see Table 1), representing a balanced mix of UN-agencies, INGOs and the IFRC. We also selected the organisations based on their varied mandates, beneficiary groups and products/services delivered. Since these attributes could influence the ways in which IHOs approach localisation, such purposeful sampling (Patton, 2002) helped cover many relevant aspects of localisation.

In total, we conducted 28 in-depth interviews with respondents from the 12 organisations. The interviewees were mostly selected through professional contact networks and by snowball sampling (Miles and Huberman, 1994). Interviewees were asked to suggest other individuals with expertise on our research topic either from the same or another IHO. We interviewed two or three experts from each organisation in order to enable triangulation of the results within the same organisation (cf. Alvesson, 2011). Many of the interviewees had major responsibilities related to logistics, with titles such as Logistics Manager, Procurement Coordinator, or similar (46.5\%). Some focussed on capacity strengthening with job titles such as Capacity Development Advisor and Resilience Advisor (21.5\%). Others worked primarily on the design and implementation of preparedness and response as an Operating Officer or Emergency Director (25\%). The study also included two interviewees $(7 \%)$, titled Senior Advisors, who were considered consultants rather than working for a specific organisation and had extensive, general experience working in the sector. These interviewees are at the core of localisation as they are responsible for implementing the strategy in their day-to-day activities and decisions. Their views on localisation are of immense importance to its success, making them central to our methodology and understanding of localisation of logistics preparedness.

The interviewees were highly experienced, having worked in the humanitarian sector between 7 and 45 years with a mean of 18.7 years. Although a majority of the interviewees $(82 \%)$ currently work at HQ-level, many of them have extended field-work experience.

\begin{tabular}{|c|c|c|c|c|}
\hline Organisation* & Type & Focus/mandate & Commodities & Interviewees \\
\hline UNFPA & UN & Reproductive health, all disasters & $\begin{array}{l}\text { Reproductive } \\
\text { health kits }\end{array}$ & I1, I2 \\
\hline UNHCR & UN & $\begin{array}{l}\text { Refugees and internally displaced } \\
\text { people, man-made disasters }\end{array}$ & Multi & $\mathrm{I} 3, \mathrm{I} 4$ \\
\hline UNICEF & UN & Children, all disasters & Multi & I5, I6 \\
\hline WFP & UN & Food, all disasters & Food & I7, I8, I9 \\
\hline WHO & UN & Health care, all disasters & Health care & I10, I11 \\
\hline CARE & INGO & Women and girls & Multi & $\mathrm{I} 12, \mathrm{I} 13$ \\
\hline MSF & INGO & Health care, all disasters & Health care & $\mathrm{I} 14, \mathrm{I} 15$ \\
\hline $\mathrm{NRC}$ & INGO & $\begin{array}{l}\text { Refugees and internally displaced } \\
\text { people, man-made disasters }\end{array}$ & Multi & I16, I17 \\
\hline Oxfam & $\begin{array}{l}\text { INGO/ } \\
\text { Federation }\end{array}$ & Poverty, all disasters & Multi & I18, I19 \\
\hline SOS & $\begin{array}{l}\text { INGO/ } \\
\text { Federation }\end{array}$ & Children, all disasters & Multi & $\mathrm{I} 20, \mathrm{I} 21$ \\
\hline WVI & INGO & Children and families, all disasters & Multi & $\mathrm{I} 22, \mathrm{I} 23$ \\
\hline IFRC & $\begin{array}{l}\text { IFRC/ } \\
\text { Federation }\end{array}$ & $\begin{array}{l}\text { Government auxiliary, natural } \\
\text { disasters }\end{array}$ & Multi & $\mathrm{I} 24, \mathrm{I} 25, \mathrm{I} 26$ \\
\hline Consultants & $\mathrm{N} / \mathrm{A}$ & Humanitarian system & $\mathrm{N} / \mathrm{A}$ & $\mathrm{I} 27, \mathrm{I} 28$ \\
\hline
\end{tabular}

Note(s): *United Nations Population Fund (UNFPA), United Nations High Commissioner for Refugees (UNHCR), United Nations Children's Fund (UNICEF), World Food Programme (WFP), World Health Organisation (WHO), CARE (CARE), Médecins Sans Frontières (MSF), Norwegian Refugee Council (NRC), Oxfam International (Oxfam), SOS Children's Villages International (SOS), World Vision International (WVI), International Federation of the Red Cross and Red Crescent Societies (IFRC)

\section{Localisation of logistics preparedness}

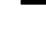


JHLSCM 11,1

Merging the interviewees' total years of experience, they have spent $53 \%$ of their time at HQ and $47 \%$ at different field levels. Their consolidated field work covered a large geographical area. The area most experienced by interviewees was Africa $(71 \%)$, followed by the Middle East (43\%), Southeast Asia (21\%), Europe (21\%), the Pacific Islands $(11 \%)$, and the Caribbean $(7 \%)$. A majority of the interviewees $(54 \%)$ worked for other humanitarian organisations previously. To secure the anonymity of the interviewees, we cannot provide further details.

\subsection{Data collection and analysis}

Using the related literature, we developed a semi-structured interview guide that we piloted on three interviewees from different IHOs (see Appendix). After the pilot tests, we slightly altered the interview guide to more clearly frame the localisation theme (cf. Yin, 2003). The interviews lasted between 75 and $110 \mathrm{~min}$ with a mean of $90 \mathrm{~min}$. The first author participated in all interviews together with one of the other authors with the purpose of applying a replication logic while reducing interviewer bias (cf. Yin, 2003). Due to a schedule conflict, one interview was performed by the first author only.

We used an online tool to transcribe $42 \mathrm{~h}$ of recorded material. Next, we coded the material in different sections and used the interview guide as a foundation for the coding process and the identification of different themes. This study focusses on IHOs' understanding of localisation of logistics preparedness and the match/gap between strategy formulation and implementation. The themes in this article therefore reflect the interviewees' overall views toward localisation (i.e. localisation trends, localisation definition, localisation vision within organisation, level of operationalisation within the organisation and the future role of the organisation). While coding the empirical material, we also observed different operationalisation aspects that were connected to the localisation views. These were opinions connected to (1) what logistics preparedness capacities to transfer, (2) to whom and (3) to which level in the organisation, forming three new themes critical for clarifying what the localisation strategy entails and how it should be implemented (cf. Neilson et al., 2008; Ateş et al., 2020)

We used Excel to code each interviewee's statement to one of the identified themes. The next step was to identify and categorise similar statements from the interviewees. Here, we followed an inductive approach to identify patterns in how interviewees viewed and intended to operationalise localisation of logistics preparedness. First, classifying the "to whom to transfer" and "to what level (where)" aspects was a straightforward process due to the limited number of actors and organisational levels in the humanitarian sector. Second, for the "what capacities to transfer" aspect, we clustered similar logistics capacities with the same aims together. As an example, capacities related to supply (e.g. procurement and framework agreements) were put in the same category. Lastly, we classified interviewees' overall localisation views based on their commonalities in terms of a range of different themes. These included localisation definition and vision, the future role of the organisation and determining who should have which responsibility related to logistics preparedness. Connected to these themes we identified four dominant views, which we discuss in detail below.

\section{Findings}

The interviewees (see Table 1) clearly observed the shift in focus from global to local humanitarian operations, with $92 \%$ observing a change in discourse. Some argued there is a need for change, as more countries become capable of carrying out a larger proportion of humanitarian assistance: "The existing model of the aid organisations is out of date. The aid 
organisations will be smaller, some will not exist and some will merge and become different forms of organisations. They will have different business models, going back to be smaller and more programmatically purposed in their role" (I27). The majority (71\%), however, claimed that such a shift is currently only being envisioned rather than operationalised, as articulated in the following quote: "The rhetoric is there, but do I actually see some physical trends or some organisations responding to these trends in a mature way? I think it is early days, I would likely say no. I think it's a fad more than it's a trend at this stage. I believe that in the next five or six years we will definitely be moving from fad to trend" (I28). To sum up, the interviewees acknowledged the need for localisation of logistics preparedness but claimed it being more an intention than a strategy to be implemented. This lack of communication and aligning the localisation strategy to the organisational goals as well as day-to-day activities form major obstacles to the localisation intents.

\subsection{Which logistics preparedness capacities to transfer}

First, we investigated interviewees' opinions regarding what logistics preparedness capacities they considered could/should be transferred to a more local level. Figure 2 summarises our findings on capacities mostly mentioned by the interviewees, independent on to whom to transfer. The capacity most advocated by the interviewees was transferring knowledge related to how to prepare and respond to disasters $(71 \%)$. Some interviewees argued for a knowledge transfer to the organisation's own offices, while others claimed that localisation is a transfer to an external actor. Interviewees were unanimous as to the importance of knowledge transfers and noted that IHOs have had decades of experience in training and acquiring the necessary knowledge. They also stressed the importance of adopting a learning-by-doing approach during the time-consuming process of knowledge transfers. This involves allowing mistakes: "Learning from mistakes is the best way, of course, but also, you can give endless trainings in logistics. But if you are then not implementing or using it, or if that does not bring you any added value in terms of potential funding, or growth of your organisation or your response, then it will not sustain" (I18).

The majority of interviewees emphasised transferring capacities connected to stockpiles and warehousing $(57 \%)$ as well as setting up SOPs, policies, routines and systems $(57 \%)$.

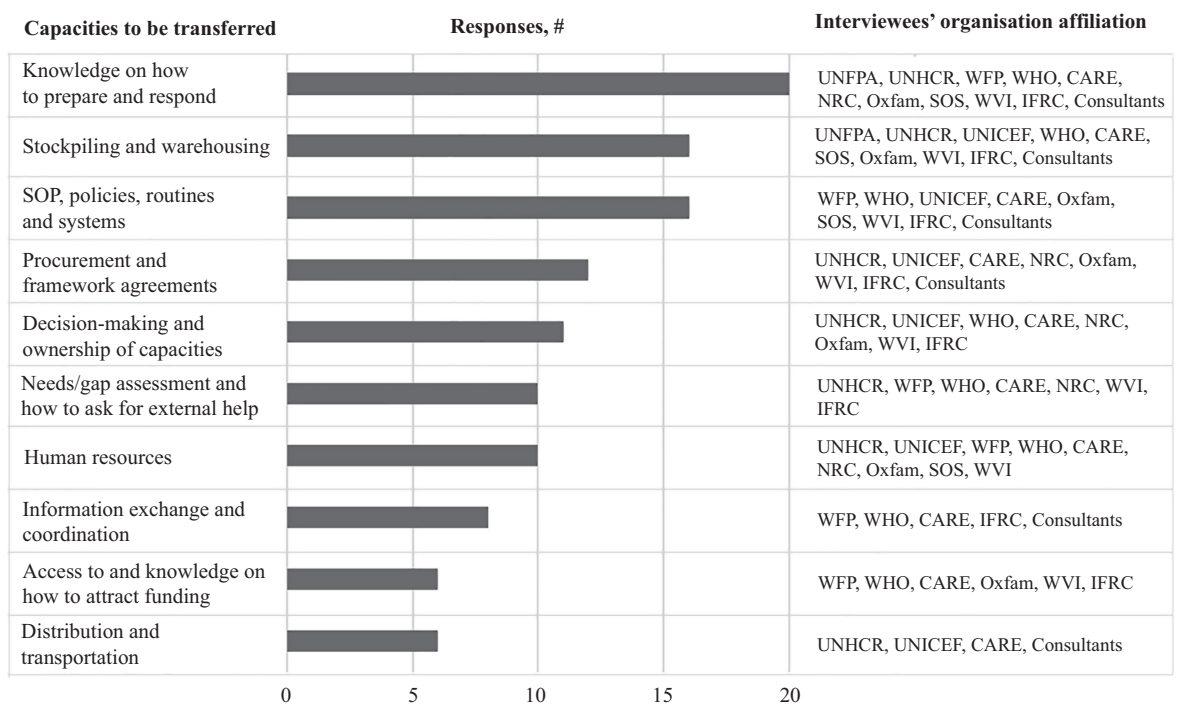

Localisation of logistics preparedness
Figure 2. What logistics preparedness capacities the IHO community intends to transfer 
JHLSCM 11,1

Interviewees highlighted having emergency stocks physically closer to beneficiaries for a more rapid response. The focus on SOPs, policies, routines and systems reveals the importance of creating structures and procedures. If a disaster occurs, the responsible actors must know how to efficiently and effectively respond: "I use the same standardised processes, documentation, and support writing for the logistics and procurement support as well as operations, and I'll train people on how to make use of that. So, in the future, when they are confronted with another situation and need to respond to some form of emergency, they have the basic templates and experience" (I13).

Interviewees $(43 \%)$ underlined the need to transfer knowledge on how to perform activities connected to procurement and framework agreements. They also emphasised procuring goods and services as locally as possible: "And in fact, we try to buy locally-locally. We even try to encourage people, working in a particular province to buy from their province. That's a bit of walking the talk, right? If you're going to try and support development in a country, you need to spend the money in that community" (I23). Related, several interviewees (39\%) highlighted decision-making and the ownership of capacities. They acknowledged there is a trend in changing from a top-down to a bottom-up approach in decision-making and ownership of capacities. National actors, whether they are local IHO offices or host governments (or other), are given more opportunities to make decisions concerning humanitarian activities and resources: "Some of this decision-making has been pushed down to regional or country office level. There is a strategic shift in how decisions are made which makes people near the field more responsible. HQ is not dictating the agenda anymore" (I16).

Needs/gap assessment and the ways in which to ask for external help was mentioned by $36 \%$, acknowledging that having logistics preparedness capacities is not enough. National/ local actors must also know when and from whom to request external help, whether that is a neighbouring country, an international organisation, or the private sector. As stated by one interviewee: "There needs to be a lot of clarity from the government around how they are going to do needs assessments, and how they are going to request specific support from UN agencies and NGOs, whether they are international NGOs, or local NGOs. In an emergency, there are a lot of people who want to help, but it is about having clarity about what you need, and having clarity around who is going to deliver that for you" (I10).

Human resources were mentioned by more than a third (36\%) of the interviewees, with many interviewees advocating for the importance of local staff working in their national offices. For example, one interviewee stated: "We have a specific policy that guides the localisation of staff. . . We want to have more and more national staff, also in key areas such as logistics manager and head of support" (I16). Some interviewees focussed on the importance of external national/local actors employing experienced staff while others emphasised the general need for experienced staff at the local level.

Information exchange and coordination $(29 \%)$ concern transferring capacities to communicate with and integrate other actors in preparedness activities. Interviewees agreed that a single actor could not take on all the responsibility, it needs to be a collaborative effort. Several other aspects were also mentioned, including platforms, systems and knowledge: "We need to identify who are the other actors in order to be sure that we can coordinate, share information and avoid duplications, so you need to have a proper information system in place" (I24).

A few interviewees $(21 \%)$ mentioned the need for transferring knowledge to national and local actors in order to attract funding. "The aim is that local actors can go straight to the donors and get the money" (I12). Some argue it should become easier for national/local actors to get access to funds. "There is more need for direct funding, or access to funding for local organisations, which is one of the biggest triggers for capacity development" (I18). Finally, interviewees stressed the need to transfer distribution and transportation capacities to a national/local actor, either internal or external $(21 \%)$. "Say for instance, that we have 
prepositioned stock in different countries around the world. Maybe it is just purely to provide access to that stock as required, and maybe just transport to the first available port in the country. And then the national organisation can take the responsibility from then onwards" (I13).

Figure 2 suggests that capacities to be transferred relate to knowledge on how to physically run a local logistics operation. The capacities in the upper half of Figure 2 include, for example, stockpiling and warehousing, routines and systems and procurement and framework agreements. Organisational capacities that are indirectly required for logistics preparedness are mentioned less frequently. The lower half of Figure 2 includes, for example, human resources, coordination and knowledge on how to attract funding. These capacities are traditionally controlled by $\mathrm{HQ}$, which could explain lower willingness to transfer those. In comparison, an explanation could be that the interviewees find it easier to transfer capacities related to logistics at a regional/national/local level, which are a part of their day-to-day activities. Strategy implementation literature acknowledges the need for communicating and clarifying decision rights and responsibilities to the implementers of the strategy. The lack of guidance and clear communication may form an obstacle to transferring capacities that traditionally belong at $\mathrm{HQ}$ as it requires HQ's strong support, training and delegation of responsibilities.

\subsection{To whom to transfer logistics preparedness capacities}

Figure 3 summarises interviewees' views on to whom they intend to transfer logistics preparedness capacities, showing that capacities' transfer to IHOs' internal, regional/ national/subnational offices dominates $(64 \%)$. The extent of this transfer, however, varies substantially. Whereas most advocated strengthening these offices, a few argued for their independence. One interviewee from CARE elaborates: "One of the ways of localising is to have some of the country programs transformed into local NGOs as a member of CARE but with their own board" (I12).

One-third of the interviewees emphasised transferring capacities to host governments $(36 \%)$, whereas a few mentioned national/local NGOs/CSOs $(18 \%)$, the private sector $(7 \%)$ and communities $(7 \%)$. These relatively low numbers can be seen in the context in which the IHOs operate. IHOs often work with permanent presence in countries, remaining in control of decisions and resources. The literature states that an organisation's structure, control and culture affect employees' behaviour in strategy implementation (Hill et al., 2015). Transferring capacities to these actors hence entails more challenges since it is historically not part of IHOs' organisational identity or culture. Some patterns can be found in interviewees' current organisation affiliations. Interviewees working for UN agencies often considered a transfer to host governments: "I think to me, it's always very clear, we have to work with the government and it's the government that leads the response that we are in support of" (I10). Interviewees working for INGOs, on the other hand, had a stronger focus on transferring to a national/local NGO: "In terms of funding, it would be mostly, nearly always, local NGOs or national NGOs in

\section{Localisation of logistics preparedness}

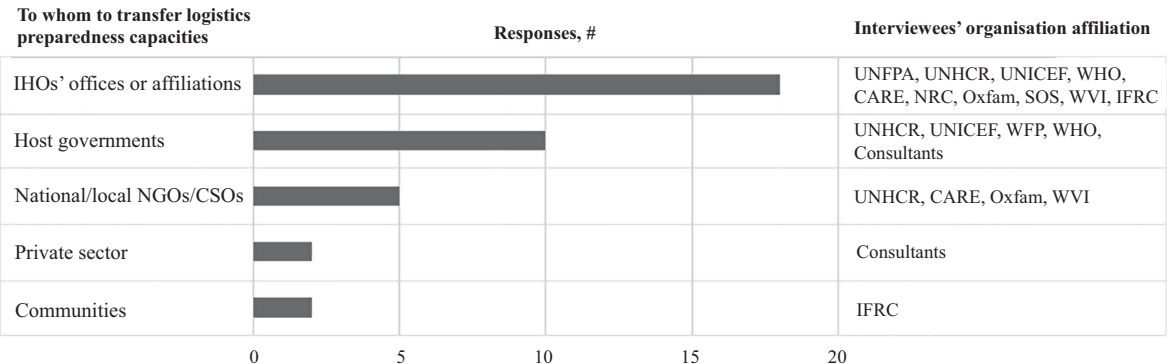

Figure 3.

To whom the IHO community intends to transfer logistics preparedness capacities 
JHLSCM 11,1

\section{4}

Figure 4.

To what level in the organisation the IHO community intends to transfer logistics preparedness capacities the country. We are trying to give them that space and promote them to take more leadership" (I18). The interviewees referred to as consultants were the only ones highlighting the private sector as a main future player in humanitarian assistance: "In terms of the shift towards localisation we need to engage businesses, large businesses and small enterprises. . . They are the ones who have most horsepower or leverage or ability to reemploy and restart economies and rebuild" (I28). Finally, a capacity transfer to communities was only mentioned by representatives from the IFRC: "Community could play a key role in receiving a warning and in acting before the disaster strikes" (I24).

In summary, our findings suggest that IHOs focus on shifting responsibilities to national/ local offices. For transfers outside the own organisation, UN organisations are more prone to transfer capacity to host governments whereas INGOs prefer to partner with national/local NGOs/CSOs. This is probably due to their different mandates and roles where the UN should support the governments while performing advocacy work and the INGOs require to work independently from host governments. The IFRC's specific mandate as national affiliates to host governments make them more prone to strengthen their own national societies.

There is little ambition to transfer logistics preparedness capacities to private sector and local communities although both could have a big role/impact. A potential explanation is the IHOs' historical control of operations and the absence of explicitly mentioning/defining relevant national and local actors in localisation initiatives. Bearing in mind that strategy implementation is successful when incorporated in daily activities, another explanation concerns the work position of our interviewees. Their daily work is to provide support mainly to host governments (at least in UN organisations) or their own organisation's offices, making those capacity transfers easier to implement. A transfer to an actor that is not a part of the daily work requires heavy communication and substantial changes in employees' objectives. Altogether, our findings show that the interviewees do not acknowledge the range of actors that are important for localisation of logistics preparedness capacities. It appears that the readiness for comprehensive implementation of the localisation strategy is still in its infancy.

\subsection{To what level (where) in the organisation to transfer logistics preparedness capacities}

This section describes how the interviewees interpreted the word "local". We specifically analysed views on where to transfer logistics preparedness capacities to. Our results suggest that interviewees hold different views, often mentioning transfer to several levels (see Figure 4). Typically, interviewees mentioned capacity transfers to the national and subnational (e.g. provincial, municipal) levels. An interviewee commented: "We will strengthen the expertise of the country office to better support the national authorities ... I would say there is a genuine desire at the leadership level in the organisation to move to a place where it identifies with local authorities, local community as strong as can possibly be" (I22). In some interviews, localisation was connected to the regional level (i.e. cluster of multiple countries), involving capacity building to collaborate, learn from and help other countries with preparedness and disaster response. One interviewee stated: "In fact, there is an emphasis on bringing the decisions closer to the ground and to the field, linked more to

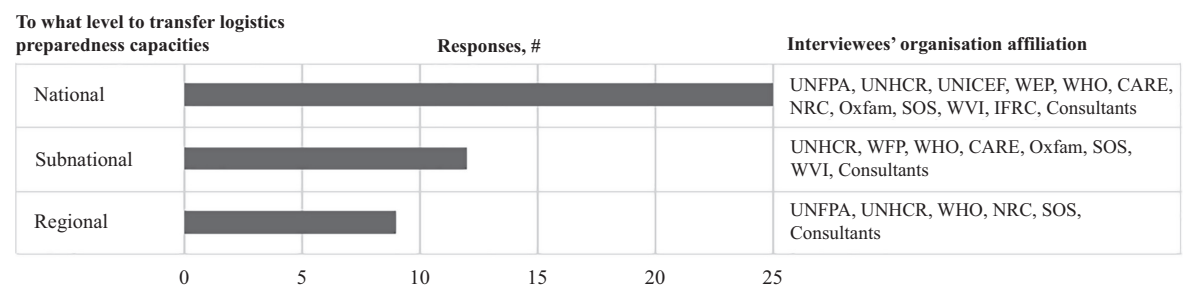


regional offices (I16)." Another interviewee adds: "For us, being prepared in terms of supply chain and logistics is more at the regional level" (I6).

In summary, there is a dominant view around transferring logistics preparedness capacities to countries (national level) and less focus on regional or subnational transfer. This may depend on the interviewees and at which level they currently work. It is likely that HQstaff work toward the regional level and therefore sees regional capacity transfer as localisation. In the same line of reasoning, a regional level employee is likely to work with national structures and considers such capacity transfer as localisation. Altogether, the operationalisation aspects (i.e. what, who and where to transfer) and Figures $2-4$ clearly show that there is no consensus on what localisation means.

\subsection{A categorisation of differing views on localisation}

The interviewees clearly did not have a universal understanding of localisation. By operationalising the concept, we identified and classified four views that encompassed interviewees' overall understanding (see Table 2): (1) decentralisation; (2) partial transfer; (3) full transfer and (4) centralisation. It was not uncommon that interviewees expressed more than one view. Several interviewees combined a decentralisation view with a partial transfer or full transfer view: "I think it'll go more and more to national. I think that trend is already there. People are really trying to strengthen the country offices and work together more with the national authorities in humanitarian response and preparedness. . I think the ultimate aim is to make countries as developed and independent as they want to be, so that will happen eventually" (I2).

Decentralisation represents the dominating view among interviewees (57\%). It entails decentralising capacities to the IHO's regional/national/subnational offices or affiliations. Primary reasons mentioned by interviewees were increasing flexibility, decreasing response times and making these offices better equipped to handle large disasters. For example, preparedness plans and response could be tailored to the country's needs and therefore be more culturally fitting and accepted. The degree of decentralisation envisioned varied substantially, with some interviewees emphasising decentralising knowledge and resources: "We really need to make sure that we are going to transfer our knowledge to the front staff. And also, we are going to invest more resources to have adequate capacity at country level, so that they can directly deal with the responses" (I19). Other interviewees advocated detaching national offices from the parent organisation: "Our governance model from our international organisation to our national offices is to build the capacity of our national offices and their governance so they become self-run" (I23). Many of the interviewees also discussed partial or full transfer to national/local, external actors in the long-term but considered strengthening their own offices as a first necessary step.

Partial transfer refers to the view that some operational logistics preparedness capacities are transferred to external, national/local actors: "The operational delivery of the assistance no longer needs to be done by the aid organisations; they need to get out of the business completely" (I27). This encompasses most logistics preparedness capacities with a few exceptions. Strategic capacities, such as fundraising, were presented as the new focus and role of IHOs. Some interviewees saw themselves as consultants, bringing the necessary expertise wherever needed. They all agreed on the need to find their new role in the humanitarian sector: "I would say that is the main question for the current traditional aid sector including our counterparts in UN agencies. It is part of reimagining our role and part in the 21th century. We can and must play our new and maturing role. What we do is convene, connect, catalyse" (I28).

Full transfer mirrors most aid organisations' ultimate goal: their work in a country is complete and they can withdraw permanent presence. This view differs from partial transfer in that all logistics preparedness capacities are envisioned to be transferred to external, national/local actors: "I think the future should be, in my mind, more and more national
Localisation of logistics preparedness 


\section{JHLSCM 11,1}

\begin{tabular}{ll}
\hline $\begin{array}{l}\text { Localisation } \\
\text { view }\end{array}$ & Content \\
\hline Decentralisation & $\begin{array}{l}\text { Transferring more } \\
\text { capacity to regional/ } \\
\text { national/subnational } \\
\text { offices or affiliations } \\
\text { but still keeping global } \\
\text { capacity for large } \\
\text { disasters }\end{array}$ \\
Partial transfer & $\begin{array}{l}\text { Transferring the } \\
\text { operational part of } \\
\text { logistics preparedness } \\
\text { capacities to external, } \\
\text { national/local actors } \\
\text { with the purpose of } \\
\text { having a more strategic } \\
\text { role in the future }\end{array}$
\end{tabular}

\section{6}

Table 2.

Classification of localisation views within the IHO community

$\begin{array}{ll}\text { Full transfer } & \text { Transferring all } \\ \text { capacities to external, } \\ \text { national/local actors } \\ \text { with the purpose of } \\ \text { withdrawing } \\ \text { international presence } \\ \text { from that country }\end{array}$

$\begin{array}{lll}\text { Illustrative quote } & \begin{array}{l}\text { Responses, } \\ \text { \# (\% of tot })\end{array} & \begin{array}{l}\text { Organisation } \\ \text { affiliation }\end{array}\end{array}$

"The vision now is that we have strong regular program, when there is not an emergency, which means that we are already in country before an emergency hits." (I6)

"It means our role is shifting to more supporting, bringing expertise, specific expertise, which would add value. Bringing more brokering type of roles, bringing stakeholders together, where we have a role and space to do that."

(I18)

\begin{tabular}{|c|c|c|}
\hline $\begin{array}{l}\text { "Localisation is } \\
\text { basically a commitment } \\
\text { toward building the } \\
\text { capacity of local and } \\
\text { national actors to be } \\
\text { able to deliver } \\
\text { humanitarian response } \\
\text { without an audience, } \\
\text { without international } \\
\text { NGOs." (I23) }\end{array}$ & $9(32 \%)$ & $\begin{array}{l}\text { UNFPA, UNHCR, } \\
\text { UNICEF, WFP, } \\
\text { WHO, CARE, WVI }\end{array}$ \\
\hline $\begin{array}{l}\text { "We have an } \\
\text { organisational supply } \\
\text { strategy set up recently } \\
\text { and there are, if I } \\
\text { remember, eight } \\
\text { objectives and none of } \\
\text { them says anything } \\
\text { about what you call } \\
\text { localisation. It's not at all } \\
\text { a strategic topic it's an } \\
\text { operational optimistic } \\
\text { topic." (I15) }\end{array}$ & $3(11 \%)$ & MSF, UNFPA \\
\hline
\end{tabular}

\author{
$16(57 \%) \quad$ NRC, CARE, \\ UNFPA, SOS, \\ IFRC, UNICEF, \\ Oxfam, WVI, \\ UNHCR, WHO
$7(25 \%) \quad$ WFP, Oxfam, WHO, Consultants

\begin{tabular}{ll}
\hline Centralisation & $\begin{array}{l}\text { No aim to make } \\
\text { capacities more local }\end{array}$
\end{tabular}


house. Challenges in ensuring high-quality and non-disrupted medical supplies through external partners comprise one reason behind this view: "The global quality of the drugs has worsened during the last 10 years. . So medical items remain in a centralised supply chain" (I14). Increased buying power and resulting economies of scale form a second reason for centralisation. One interviewee applies this argument to medical kits supply: "You need to have it large scale. Otherwise there is no manufacturer, or you would have to pay very high prices" (I1).

To summarise, a strong majority agrees on the necessity to localise logistics preparedness; only a small percentage argue for centralisation. More than half of the interviewees view localisation as a shift from HQ to strengthening their own, local offices or affiliations, which corresponds to Van Brabant and Patel's (2018) "decentralisation interpretation". A fairly strong percentage envision capacities eventually being transferred to external, national/local actors, which corresponds to a "transformation interpretation" (cf. Van Brabant and Patel, 2018). The UN organisations appear more eager to transfer capacities to external actors. A potential explanation is their role in supporting host governments. Several interviewees claim that host governments are increasingly committed and able to lead humanitarian action and are therefore requesting more responsibility. The UN's sources of funding may also provide the necessary flexibility to transfer capacities externally, whereas smaller INGOs may be more pressured to adhere to their donors' requirements and therefore want to keep control of the operations in-house.

There are quite a few overlaps in localisation views with interviewees often imagining a strengthening of both internal and external capacities in the future. The interviewees' different views diverge from the localisation intents and pose a major obstacle to its implementation. The formulated localisation strategy may lack details, causing confusion in and among organisations and individuals. The organisations may also have failed in providing visionary leadership or communication throughout the whole organisation. Another potential explanation is that organisations and/or employees choose to interpret localisation differently as it can be considered a threat to their survival.

\subsection{Summary of localisation of logistics preparedness capacities}

Our findings show that localisation of logistics preparedness is surrounded by ambiguity within the IHO community, with varying views to its meaning (not accounting for those lacking a localisation aim). To advance our theoretical understanding of the phenomenon, we used the results/analysis of the previous sections to build a coherent framework (see Figure 5). We included the percentages connected to the different perceptions of localisation to visualise the diversity in the interviewees' statements.

The framework serves two purposes. First, it clearly demonstrates the widely different views of what localisation of logistics preparedness constitutes, even within the same IHO, and hence points to a major obstacle to succeed with implementing the localisation strategy. Successful strategy implementation hinges on the clarity of a common strategy, aligned with the organisational goals, communicated throughout the whole organisation and integrated in the day-to-day objectives of employees. Ten out of twelve IHOs that the interviewees represent have committed to the Grand Bargain. All the elements important for strategy implementation are largely missing, implying that each IHO needs a clear vision and a guiding model that both fit the overall localisation aims. This offers an explanation to why localisation actions have been scarce.

Second, while showing different views, our framework at the same time provides a remedy to overcoming some of the obstacles for implementing the localisation strategy. In the framework, we operationalise logistics preparedness localisation strategies. To move forward, discussions on localisation topics need a shared language as well as clear and
Localisation of logistics preparedness 


\section{JHLSCM}

11,1

\section{8}

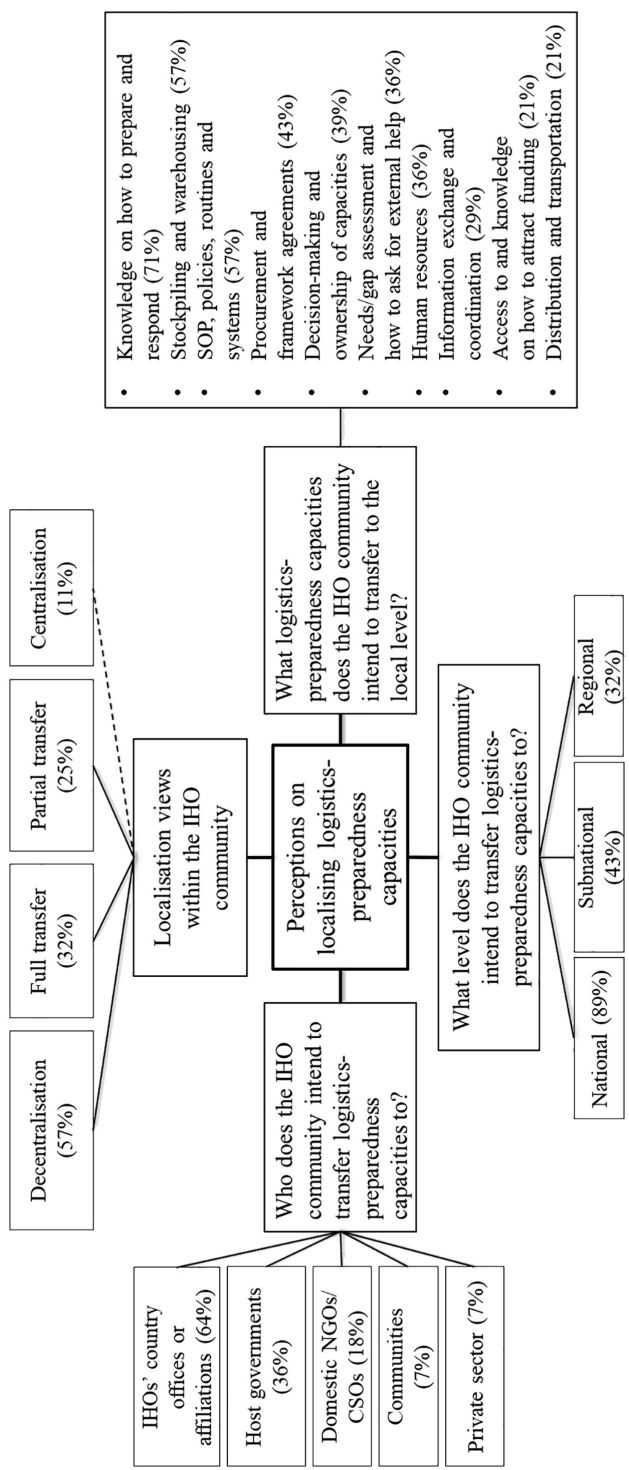

Figure 5.

Framework covering interviewees' perceptions of localisation 
concise definitions. The humanitarian community's strategic aim of localisation has been struggling with those basics, leading to a huge gap between strategy formulation and implementation. This is where our framework provides an important platform, contributing to establish a common understanding and enable clearer communication about localisation. Considering the diverse views in the framework, we argue that it is important to distinguish capacity transfers to internal IHO offices (i.e. decentralisation) from external, national/local actors (i.e. partial and full transfer). We advocate that the term localisation should only be used for the latter, which is in line with existing reports (e.g. Fabre, 2017; ICVA, 2018; Van Brabant and Patel, 2018). As shown in strategy implementation literature, mixing the two risks diluting the term "localisation" and creating confusion. This could lead to localisation commitments, such as the Grand Bargain and Charter for Change, losing their intended impact.

To advance localisation of logistics preparedness, IHOs must do a better job on aligning an agreed upon localisation strategy to their organisational goals. The literature states that strategy implementation ultimately consists of the numerous daily decisions made by employees. Localisation is therefore dependent on how well organisations manage to integrate strategic goals in their employees' objectives and activities. The framework presented in this paper offers an important step in overcoming the obstacles to implement the formulated localisation strategy.

\section{Concluding discussion}

Taking the IHO community's perspective, our study aimed to enhance understanding of the localisation of logistics preparedness capacities. A large part of the humanitarian community supports localisation as a common strategy to shift responsibility and capacity to national and local actors in humanitarian aid (see, e.g. the Grand Bargain and the Charter for Change initiatives). IHOs' role to implement that strategy is explicit in both localisation initiatives and in practitioners' reports. As Bennett et al. (2016, p. 70) state: "This also requires a commitment by UN agencies and large, multi-mandate NGOs to embrace difficult changes in the approach and architecture under which the sector currently operates".

Interviews with 28 humanitarian professionals showed that localisation is a prevalent topic in logistics but concrete initiatives are largely missing. By operationalising the concept, our findings confirmed the absence of a cohesive understanding of localisation, with confusion between strengthening external actors and internal national/local offices. This finding is very much in line with Van Brabant and Patel's (2018) separation between "decentralisation interpretation" and "transformation interpretation". This is an important finding, as it highlights dissonance between the initial motivation for and current views on localisation. It suggests that a substantial part of the humanitarian community which has the responsibility to implement the strategy does not agree on the strategy's direction. The term "localisation" could be the cause of additional confusion as it refers to another phenomenon in the commercial context (cf. Wu and Jia, 2018). The lack of a unified understanding and strategic consensus are a major obstacle to successful localisation implementation. It may be necessary to reformulate the localisation strategy and align it much more explicitly with the organisational goals. The literature further emphasises the importance of strong communication to all employees alongside instructions on how to implement the strategy in their day-to-day work. The IHOs should therefore provide the employees with the resources and incentives to carry it through, for example by creating an implementation model and guide.

The interviewees lacked a shared language and to a certain extent disagreed on what capacities to transfer to which level in the organisation. We saw little tendency to localise capacities indirectly related to logistics, such as coordination skills and knowledge on how to 
JHLSCM 11,1

100 attract funding. This is an important insight, as the division between direct and indirect logistics capacities is not reflected in key documents on localisation. One possible explanation is that our interviewees do not have the decision authority or control over these capacities. This is pointed out as an important obstacle in strategy implementation literature. The lack of decision authority may also explain the low ambition to transfer to private sector and local communities. This however requires further investigations. Related, considering that a country cannot handle any large-scale disaster by itself, it is worthwhile to explore the strengthening of national/local actors' capacities to integrate international help.

Our findings suggest that the readiness for comprehensive localisation is still in its infancy. We contribute to literature on logistics aspects of preparedness, localisation and local capacity building (cf. Sheppard et al., 2013) by submitting a framework to concretise localisation of logistics preparedness. To avoid diluting the term, we clearly distinguish localisation from decentralisation where responsibility would remain in the hands of organisations with foreign aid structures (cf. Bealt and Mansouri, 2018). IHOs can use our framework for verbalising their intended approach. This does not mean that localisation efforts should be identical for all organisations. We argue, however, that a clear view and common language are necessary to advance localisation initiatives, particularly logistics preparedness ones. Beyond logistics, our framework could also provide guidance to Grand Bargain signatories struggling with basic definitions (cf. Els, 2018). Unclear definitions risk losing the intended impact of localisation initiatives. It could also explain why the aim to directly transfer $25 \%$ of funding to national and local actors by 2020 is far from being achieved, with only 2.1\% reached until 2019 (Thomas and Urquhart, 2020). Strategy implementation literature indeed highlights the importance of quantification of vision but there are other obstacles to consider. It can be argued that the goal of $25 \%$ is currently working against existing power structures and localisation in general may be interpreted as a threat to the IHOs' survival, suggesting a high internal resistance within IHOs (cf. Hrebiniak, 2006; Sharp and Brock, 2012). One report (A4EP, 2019) argues that IHOs are trying to bypass the $25 \%$ aim by directing the funding to their national offices instead of external actors. A high-level quantification of vision must be accompanied by more tangible and achievable goals, implying the need for IHOs to create better and more integrated performance measurements. Handling internal resistance, both at an organisational and an individual level, is perhaps an even bigger challenge. Strategy implementation literature shows that visionary leadership and reducing uncertainties related to the localisation change process could improve employees' motivation and strategic commitment.

Further research is required to support the advancement of localisation. Methodologically, our inductive classification of localisation views needs to be validated and triangulated through quantitative research (Von Krogh et al., 2012). Case studies could provide in-depth insights by investigating individual organisations. A secondary-source analysis of the numerous practitioner reports on localisation could also offer a better understanding to various aspects.

Our paper focussed on IHOs, but localisation initiatives engage several other stakeholders. As seen in strategy implementation literature, the role and impact of the different stakeholders make implementation for non-profit organisations even more difficult than for commercial organisations (Lewis et al., 2001). The perspectives of host governments, national and local NGOs/CSOs, private sector and communities are important considering that they are the targets of the implementation process. Also, the role and view of donors need to be clarified in the longer term. Donors are key stakeholders in changing the fundamental structure and creating the context in which the localisation strategy can be implemented.

More research is hence needed to fully comprehend the meaning of localisation and propose a common and shared definition. Based on the insights from practitioner reports and our study, we however offer a preliminary definition that clarifies the key aspects of a 
formulated localisation strategy. We build on the definition of logistics preparedness provided by Jahre et al. (2016) to understand localisation of logistics preparedness as: "The process of transferring logistics preparedness capacities from IHOs to external, national/local actors, with the purpose of strengthening those actors to independently manage disasters and, when needed, have the capacity to integrate international help in the disaster relief effort". In this definition, we highlight the operational function of logistics preparedness and suggest that it currently resides with IHOs. We argue that an actual capacity transfer of logistics preparedness from IHOs to external, national/local actors is needed to succeed with localisation aims. This preliminary definition can serve as a starting point for future research. Considering that localisation is multi-disciplinary our logistics focus needs to be augmented by social, financial and environmental considerations. Future research could also highlight other disaster phases, such as mitigation measures to strengthen country resilience.

It is also worthwhile to explore the influence of context. Several reasons for pursuing centralisation, decentralisation, or localisation are context- and organisation-specific. Examples include mandate and role of the organisation, country stability, market characteristics, product characteristics and service attributes. A contingency approach is therefore necessary when organisations develop strategies for localisation of logistics preparedness. Furthermore, a clearer understanding is required of both the benefits and the risks of different approaches to localisation. One promising avenue for future research is to use the literature on multinational companies (MNCs) that can be considered the commercial equivalent of IHOs. Both are large, global actors with the aim of serving customers/ beneficiaries with a competitive/beneficial product or service. MNCs have, for a long time, faced strategic choices similar to those of IHOs. Studying MNC literature could thus further explain IHOs' choice between centralisation, decentralisation and localisation.

\section{References}

A4EP (2019), "IASC definition of 'local' and 'national actors' - a barrier to achieving Grand Bargain localisation commitments", available at: https://reliefweb.int/report/world/iasc-definitionlocal-and-national-actors-barrier-achieving-grand-bargain-localisation (accessed 20 November 2019).

Agenda for Humanity (2016), "United Nations office for the coordination of humanitarian affairs", available at: https://www.agendaforhumanity.org/summit (accessed 10 March 2019).

Alexander, L.D. (1985), “Successfully implementing strategic decisions”, Long Range Planning, Vol. 18 No. 3, pp. 91-97.

Alexander, L.D. (1991), "Strategy implementation: nature of the problem”, International Review of Strategic Management, Vol. 2 No. 1, pp. 73-91.

Alvesson, M. (2011), Interpreting Interviews, Sage, London.

Ateş, N.Y., Tarakci, M., Porck, J.P., van Knippenberg, D. and Groenen, P.J.F. (2020), "The dark side of visionary leadership in strategy implementation: strategic alignment, strategic consensus, and commitment", Journal of Management, Vol. 46 No. 5, pp. 637-665.

Balcik, B., Beamon, B.M., Krejci, C.C., Muramatsu, K.M. and Ramirez, M. (2010), "Coordination in humanitarian relief chains: practices, challenges and opportunities", International Journal of Production Economics, Vol. 126 No. 1, pp. 22-34.

Barbelet, V. (2018), “As local as possible, as international as necessary: understanding capacity and complementarity in humanitarian action", available at: https://www.odi.org/publications/11238local-possible-international-necessary-understanding-capacity-and-complementarityhumanitarian (accessed 12 August 2020).

Bealt, J. and Mansouri, S.A. (2018), "From disaster to development: a systematic review of communitydriven humanitarian logistics", Disasters, Vol. 42 No. 1, pp. 124-148. 
JHLSCM 11,1

Ben-Ner, A. and Siemsen, E. (2017), "Decentralization and localization of production: the organizational and economic consequences of additive manufacturing (3d printing)", California Management Review, Vol. 59 No. 2, pp. 5-23.

Bennett, C., Foley, M. and Pantuliano, S. (2016), "Time to let go: remaking humanitarian action for the modern era", available at: https://www.odi.org/sites/odi.org.uk/files/resource-documents/10422. pdf (accessed 25 October 2019).

Bhamra, R., Dani, S. and Burnard, K. (2011), "Resilience: the concept, a literature review and future directions", International Journal of Production Research, Vol. 49 No. 18, pp. 5375-5393.

Bhattacharya, S., Hasija, S. and Van Wassenhove, L.N. (2014), "Designing efficient infrastructural investment and asset transfer mechanisms in humanitarian supply chains", Production and Operations Management, Vol. 23 No. 9, pp. 1511-1521.

Charter4Change (2019), “CAFOD”, available at: https://charter4change.org (accessed 4 March 2019).

Collinson, S. (2016), "Constructive deconstruction: making sense of the international humanitarian system", available at: https://www.odi.org/sites/odi.org.uk/files/resource-documents/10734.pdf (accessed 10 January 2020).

Coppola, D.P. (2007), Introduction to International Disaster Management, Butterworth Heinemann, Burlington.

CRED (2018), Advanced Search, Université Catholique de Louvain, Brussels, available at: www.emdat. be/advanced_search/index.html.

Currion, P. (2018), "Network humanitarianism", available at: https://www.odi.org/sites/odi.org.uk/files/ resource-documents/12202.pdf (accessed 25 October 2019).

De Geoffroy, V. and Grunewald, F. (2017), "More than the money: localisation in practice", available at: https://www.trocaire.org/resources/policyandadvocacy/more-than-the-money-localisationpractice (accessed 12 August 2020).

Dube, N., Van der Vaart, T., Teunter, R.H. and Van Wassenhove, L.N. (2016), "Host government impact on the logistics performance of international humanitarian organisations", Journal of Operations Management, Vols 47-48, pp. 44-57.

Edmondson, A.C. and McManus, S.E. (2007), "Methodological fit in management and research field", Academy of Management Review, Vol. 32 No. 4, pp. 1155-1179.

Els, C. (2018), "On the road to 2020: Grand Bargain commitment to support national and local responders", available at: https:/www.trocaire.org/resources/policyandadvocacy/road-2020grand-bargain-commitment-support-national-and-local-responders (accessed 9 October 2019).

Fabre, C. (2017), "Localising the response", available at: https://www.oecd.org/development/ humanitarian-donors/docs/Localisingtheresponse.pdf (accessed 25 September 2019).

Fast, L. and Bennett, C. (2020), "From the ground up: it's about time for local humanitarian action", available at: https://www.odi.org/publications/16991-ground-it-s-about-time-local-humanitarianaction (accessed 5 June 2020).

Haddow, G.D., Bullock, J.A. and Coppola, D.P. (2010), Introduction to Emergency Management, 4th ed., Butterworth Heinemann, Burlington, E-book.

Hill, C.W., Jones, G.R. and Schilling, M.A. (2015), Strategic Management: Theory \& Cases: An Integrated Approach, Cengage Learning, Stamford, CT.

Holguín-Veras, J., Jaller, M. and Wachtendorf, T. (2012a), "Comparative performance of alternative humanitarian logistic structures after the Port-Au-Prince earthquake: ACEs, PIEs, and CANs", Transportation Research Part A: Policy and Practice, Vol. 46 No. 10, pp. 1623-1640.

Holguín-Veras, J., Jaller, M., Van Wassenhove, L.N., Pérez, N. and Wachtendorf, T. (2012b), "On the unique features of post-disaster humanitarian logistics", Journal of Operations Management, Vol. 30 Nos 7-8, pp. 494-506.

Hrebiniak, L.G. (2006), "Obstacles to effective strategy implementation”, Organizational Dynamics, Vol. 35 No. 1, pp. 12-31. 
ICVA - International Council of Voluntary Agencies (2018), "Localisation examined - an ICVA briefing paper", available at: https://www.icvanetwork.org/resources/localisation-examinedicva-briefing-paper (accessed 1 October 2019).

Jahre, M. (2017), "Humanitarian supply chain strategies - a review of how actors mitigate supply chain risks", Journal of Humanitarian Logistics and Supply Chain Management, Vol. 7 No. 2, pp. 82-101.

Jahre, M., Pazirandeh, A. and Van Wassenhove, L. (2016), "Defining logistics preparedness: a framework and research agenda", Journal of Humanitarian Logistics and Supply Chain Management, Vol. 6 No. 3, pp. 372-398.

Kovács, G. and Spens, K. (2007), "Humanitarian logistics in disaster relief operations", International Journal of Physical Distribution \& Logistics Management, Vol. 37 No. 2, pp. 99-114.

Kovács, G. and Spens, K. (2011), "Trends and developments in humanitarian logistics - a gap analysis", International Journal of Physical Distribution \& Logistics Management, Vol. 41 No. 1, pp. 32-45.

Kunz, N. and Gold, S. (2017), "Sustainable humanitarian supply chain management - exploring new theory", International Journal of Logistics Research and Applications, Vol. 20 No. 2, pp. 85-104.

Kunz, N., Van Wassenhove, L.N., Besiou, M., Hambye, C. and Kovács, G. (2017), "Relevance of humanitarian logistics research: best practices and way forward", International Journal of Operations \& Production Management, Vol. 37 No. 11, pp. 1585-1599.

Lee, E. and Puranam, P. (2016), "The implementation imperative: why one should implement even imperfect strategies perfectly", Strategic Management Journal, Vol. 37 No. 8, pp. 1529-1546.

Lewin, R., Besiou, M., Lamarche, J.-B., Cahill, S. and Guerrero-Garcia, S. (2018), "Delivering in a moving world...looking to our supply chains to meet the increasing scale, cost and complexity of humanitarian needs", Journal of Humanitarian Logistics and Supply Chain Management, Vol. 8 No. 4, pp. 518-532.

Lewis, L.K., Hamel, S.A. and Richardson, B.K. (2001), "Communicating change to nonprofit stakeholders: models and predictors of implementers' approaches”, Management Communication Quarterly, Vol. 15 No. 1, pp. 5-41.

Méheux, K., Dominey-Howes, D. and Lloyd, K. (2010), "Operational challenges to community participation in post-disaster damage assessments: observations from Fiji”, Disasters, Vol. 34 No. 4, pp. 1102-1122.

Metcalfe-Hough, V., Poole, L., Bailey, S. and Belanger, S. (2018), “Grand Bargain annual independent report 2018”, available at: https://www.agendaforhumanity.org/initiatives/3861 (accessed 4 March 2019).

Miles, M.B. and Huberman, A.M. (1994), Qualitative Data Analysis: An Expanded Sourcebook, Sage Publications, Thousand Oaks, CA.

Neilson, G., Martin, K. and Powers, E. (2008), “The secrets to successful strategy execution”, Harvard Business Review, Vol. 86 No. 6, pp. 60-70.

Nurmala, N., de Vries, J. and de Leeuw, S. (2018), "Cross-sector humanitarian-business partnerships in managing humanitarian logistics: an empirical verification", International Journal of Production Research, Vol. 56 No. 21, pp. 6842-6858.

Pardasani, M. (2006), "Tsunami reconstruction and redevelopment in the Maldives: a case study of community participation and social action", Disaster Prevention and Management: An International Journal, Vol. 15 No. 1, pp. 79-91.

Patton, M.Q. (2002), Qualitative Research and Evalutation Methods, 3rd ed., Sage, London.

Pedraza-Martinez, A., Stapleton, O. and Van Wassenhove, L. (2011), "Field vehicle fleet management in humanitarian operations: a case-based approach", Journal of Operations Management, Vol. 29 No. 5, pp. 404-421.

Localisation of logistics preparedness 
JHLSCM 11,1

Perry, M. (2007), "Natural disaster management planning: a study of logistics managers responding to the tsunami”, International Journal of Physical Distribution and Logistics Management, Vol. 37 No. 5, pp. 409-433.

Porck, J.P., van Knippenberg, D., Tarakci, M., Ates, N.Y., Groenen, P.J.F. and De Haas, M. (2020), "Do group and organizational identification help or hurt intergroup strategic consensus?”, Journal of Management, Vol. 46 No. 2, pp. 234-260.

Prasanna, S.R. and Haavisto, I. (2018), "Collaboration in humanitarian supply chains: an organisational culture framework", International Journal of Production Research, Vol. 56 No. 17 , pp. 5611-562.

Ramalingam, B., Gray, B. and Cerruti, G. (2013), "Missed opportunities: the case for strengthening national and local partnership-based humanitarian responses", available at: https:/policypractice.oxfam.org.uk/publications/missed-opportunities-the-case-for-strengthening-nationaland-local-partnership-302657 (accessed 19 August 2020).

Robson, C. (2002), Real World Research: A Resource for Social Scientists and Practitioner-Researchers, Blackwell Publishers, Oxford.

Roepstorff, K. (2020), "A call for critical reflection on the localisation agenda in humanitarian action”, Third World Quarterly, Vol. 41 No. 2, pp. 284-301, doi: 10.1080/01436597.2019.1644160.

Schwarz, G.M. and Stensaker, I. (2014), "Time to take off the theoretical straightjacket and (Re-) introduce phenomenon-driven research", The Journal of Applied Behavioral Science, Vol. 50 No. 4, pp. 478-501.

Sharp, Z. and Brock, D.M. (2012), "Implementation through risk mitigation: strategic processes in the nonprofit organization", Administration \& Society, Vol. 44 No. 5, pp. 571-594.

Sheppard, A., Tatham, P., Fisher, R. and Gapp, R. (2013), "Humanitarian logistics: enhancing the engagement of local populations", Journal of Humanitarian Logistics and Supply Chain Management, Vol. 3 No. 1, pp. 22-36.

Stoddard, A., Harmer, A., Haver, K., Taylor, G. and Harvey, P. (2015), "The state of the humanitarian system", available at: https://www.alnap.org/help-library/the-state-of-the-humanitarian-systemreport-2015 (accessed 12 January 2020).

Stumpf, J., Guerrero-Garcia, S., Lamarche, J.B., Besiou, M. and Rafter, S. (2017), "Supply chain expenditure \& preparedness investment opportunities in the humanitarian context [online]", available at: https:/www.actioncontrelafaim.org/en/publication/supply-chain-expenditurepreparedness-investment-opportunities-in-the-humanitarian-context/ (accessed 15 May 2019).

Thomas, A. and Urquhart, A. (2020), "Global humanitarian assistance report 2020", available at: https://devinit.org/resources/global-humanitarian-assistance-report-2020 (accessed 20 August 2020).

UNISDR (2019a), "Sendai framework for disaster risk reduction”, available at: https://www.unisdr.org/ we/coordinate/sendai-framework (accessed 8 January 2019).

UNISDR (2019b), “Terminology”, available at: https://www.unisdr.org/we/inform/terminology (accessed 8 January 2019).

United Nations (2019), "Sustainable development goals", available at: https://sustainabledevelopment. un.org/sdgs (accessed 25 September 2019).

Van Brabant, K. and Patel, S. (2018), "Localisation in practice: seven dimensions of localisation", available at: https://www.preventionweb.net/publications/view/59895 (accessed 29 November 2019).

Van Wassenhove, L. (2006), "Humanitarian aid logistics: supply chain management in high gear", Journal of the Operational Research Society, Vol. 56 No. 5, pp. 475-489.

Von Krogh, G., Rossi-Lamastra, C. and Haefliger, S. (2012), "Phenomenon-based research in management and organisation science: when is it rigorous and does it matter", Long Range Planning, Vol. 45 No. 4, pp. 277-298. 
Wall, I. and Hedlund, K. (2016), Localisation and Locally-Led Crisis Response: A Literature Review, Local to Global Protection, available at: http://www.local2global.info/wp-content/uploads/ L2GP_SDC_Lit_Review_LocallyLed_June_2016_final.pdf (accessed 15 October 2019).

Wu, Z. and Jia, F. (2018), "Toward a theory of supply chain fields - understanding the institutional process of supply chain localization”, Journal of Operations Management, Vols 58-59, pp. 27-41.

Localisation of logistics preparedness

Yin, R. (2003), Case Study Research: Design and Methods, Sage Publications, Thousand Oaks, Calif. Strategy, Vol. 23 No. 1, pp. 30-34.

Zarei, M.H., Carrasco-Gallego, R. and Ronchi, S. (2019), "To greener pastures: an action research study on the environmental sustainability of humanitarian supply chains", International Journal of Operations \& Production Management, Vol. 39 No. 11, pp. 1193-1225.

\section{Corresponding author}

Lina Frennesson can be contacted at: lina.frennesson@tlog.lth.se 


\section{JHLSCM 11,1 \\ Appendix \\ Interview guide}

1) Looking forward 5-10 years, how do you believe that functions such as sourcing, procurement, transportation, distribution, warehousing and programming in terms of preparedness will change?

i. What changes and/or trends do you see in the future? What are the reasons behind these changes/trends? (strategically/operationally)

ii. (Has there been any major changes in the last 5 or 10 years on how you work with these functions?) Any concrete examples?

2) Do you agree with the statement that there currently, in the humanitarian community, is a shift in focus from global to local operations when it comes to preparing for emergencies?

i. Is a more localised approach also reflected in the activities concerning procurement, sourcing, distribution, transportation, warehousing and programming? Please give some concrete examples.

ii. How would you define localisation? What does it mean for your organisation?

iii. Are you currently running any initiatives for developing preparedness capacity for supply chain functions at a local level?

iv. Do you as an organisation have a strategy or strategic approach for localising functions such as procurement, sourcing, distribution, transportation, warehousing and programming?

v. Have you developed any systematic framework to guide the localisation process of preparedness?

vi. How is the correlation between strategy set by $\mathrm{HQ}$ and the work at the field?

3) How do you perceive your roles and responsibilities will change with increasing localisation?

i. What is your current ability to change to a more localised approach?

ii. What is needed to increase the ability to change? What capabilities are needed?

iii. How are roles and responsibilities divided between $\mathrm{HQ}$, regional, and local level? Will these change with increasing localisation?

4) What characteristics are necessary for a country/country office to be able to prepare for emergencies in terms of the abovementioned supply chain functions?

i. How do you assess which countries that can develop or have the SC preparedness capacity in place to take responsibility for disaster preparedness?

ii. (How) does your organisation adjust its initiatives to localise preparedness capacities accordingly?

5) How does your organisation in preparing for disasters collaborate with other actors (other IHOs, private sector, public sector, government etc) in functions such as procurement, sourcing, distribution, transportation, warehousing and programming?

i. How will these collaborations change in the future?

ii. Will actors such as government and private sector play a different role in the future with increasing localisation? If so, how? 